\title{
บusisersaly
}

\section{'Making the best of what we have': The lived experiences of community psychiatric nurses, day centre managers, and social workers supporting clients with dementia attending a generic day care service}

Laird, L. EA., McGurk, P., Reid, B., \& Ryan, A. (2017). 'Making the best of what we have': The lived experiences of community psychiatric nurses, day centre managers, and social workers supporting clients with dementia attending a generic day care service. International Journal of Older People Nursing, 0, 1-9. https://doi.org/10.1111/opn.12157

Link to publication record in Ulster University Research Portal

Published in:

International Journal of Older People Nursing

Publication Status:

Published online: 29/06/2017

DOI:

10.1111/opn. 12157

Document Version

Author Accepted version

\section{General rights}

Copyright for the publications made accessible via Ulster University's Research Portal is retained by the author(s) and / or other copyright owners and it is a condition of accessing these publications that users recognise and abide by the legal requirements associated with these rights.

\section{Take down policy}

The Research Portal is Ulster University's institutional repository that provides access to Ulster's research outputs. Every effort has been made to ensure that content in the Research Portal does not infringe any person's rights, or applicable UK laws. If you discover content in the Research Portal that you believe breaches copyright or violates any law, please contact pure-support@ulster.ac.uk. 
Title

'Making the best of what we have': The lived experiences of community psychiatric nurses, day centre managers, and social workers supporting clients with dementia attending a generic day care service

\section{Authors}

${ }^{*}$ Dr Elizabeth A Laird

Lecturer of Nursing

School of Nursing

Ulster University

Northland Rd,

Londonderry, Northern Ireland, BT48 7JL

Email: ea.laird@ulster.ac.uk

Tel: $+44(0) 2871675006$

*Dr Laird is the corresponding author

Mrs Phyllis McGurk

Social Worker and Care Manager

Primary Care and Older Persons Team

Western Health and Social Care Trust.

Londonderry, Northern Ireland.

Email:phylis.mcGurk@westerntrust.hscni.net

Dr Bernie Reid

Lecturer of Public Health 
School of Nursing

Ulster University

Northland Rd,

Londonderry, Northern Ireland, BT48 7JL

Email: bb.reid@ulster.ac.uk

Professor Assumpta Ryan

Professor of Ageing and Health

Institute of Nursing and Health Research

Ulster University

Northland Rd,

Londonderry, Northern Ireland, BT48 7JL

Email: aa.ryan@ulster.ac.uk

\section{Acknowledgement}

The authors express their gratitude to all who participated in this study for giving of their time, despite competing commitments. 


\section{Abstract}

Background. In light of international ageing demographics and strategy towards social inclusion, it is anticipated that demand for generic day care services for clients living with and without dementia will increase.

Aim and Objectives. This study explored the experiences and perspectives of community psychiatric nurses, day centre managers and social workers about supporting clients living with and without dementia attending a generic day care service. The purpose of the study was to elucidate approaches that enable clients living with dementia to access and derive benefit from the service.

Design and Methods. A descriptive qualitative design utilised three focus groups for data collection. Community psychiatric nurses $(n=4)$, day centre mangers $(n=4)$ and social workers $(n=12)$ participated in the study. Data analysis informed a narrative description of the approaches that support adults living with dementia in day care.

Findings. An exhaustive description is encapsulated in five key themes. These are 'easing the transition to day care', 'proactively managing supervision and complexity of need', 'sustaining the person and family carer', making the best of what we have' and 'encountering a need for change'. The data conveyed a sensitivity to the life story and needs of clients with dementia. Whilst the data revealed deficits in the physical environment of the centres, there were indications of the generation of a positive social environment.

Conclusions. A generic day care service that provides an integrated blend of care and treatment and social and recreational support to older adults, irrespective of whether they have or have not dementia, is realistic and manageable. The routine of day centre attendance may have value in sustaining clients with dementia and family care-giving relationships.

Implications for practice. Approaches to support the attendance of clients with dementia at day care include home visits, life story work, pro-active supervision and careful planning of social groupings and recreational activities.

Key words: day care, dementia, family carers, social inclusion 


\section{What does this research add to existing knowledge in gerontology?}

- An integrated model of day care, that addresses assessment, treatment, social and recreational support needs of older adults, irrespective of whether they have or have not dementia, is realistic and manageable.

- Groups of community psychiatric nurses, day centre managers and social workers perceive that the routine of day centre attendance can sustain clients with dementia and family care-giving relationships.

- Approaches to support the attendance of clients with dementia at day care include home visits, life story work, pro-active supervision and careful planning of social groupings and recreational activities.

\section{What are the implications of this new knowledge of nursing care with older adults?}

- The contribution of interdisciplinary team working involving community psychiatric nurses, social workers and day centre managers in community care with older adults.

- Promoting day care attendance as an approach to healthy and active ageing.

\section{How could the findings be used to influence policy or practice or research or education?}

- Pre-registration mental health and adult branch nursing education programmes should include placements in generic day centre services to promote a positive view of socially inclusive and active ageing.

- Interdisciplinary groups comprising community psychiatric nurses, day centre managers, social workers and service managers should be able to address local travel time restraints that may be posing an inequity in service provision. 


\section{Introduction}

Ageing demographics and increased prevalence of dementia are global phenomena. In response, strategy and policy have aligned with active ageing (Alzheimer's Disease International, 2012; World Health Organisation, 2012). Day care has emerged as one mechanism for enhancing activity and quality of life in older age (Weir \& Fouche, 2015). Cahill et al. (2012) have differentiated between generic, dementia-focused, and dementia-specific day centre services. A generic day centre service is designed to offer support to the general population of older adults, but may also accommodate older adults living with dementia. This article reports on a study undertaken in the United Kingdom that explored experiences and perspectives of supporting clients in a generic older adult day centre service.

\section{Background}

The literature indicates that day centre attendance is associated with enhanced mental wellbeing for clients with dementia. Clients place value on the opportunities provided for engagement in meaningful social interaction (Brataas et al., 2010; Dabelko-Schoney \& King, 2010). In addition, the range of activities offered in centres can promote pleasurable anticipation and a sense of satisfaction (Tse \& Howie, 2005; Dabelko-Schoney \& King, 2010). There is also some evidence to support an association between day care and enhancements in appetite, agility, communication and sleep pattern (Chalfont, 2011).

Clients and their family carers have positively appraised the knowledge, skill and ability of day centre staff to address complex needs, citing these among the main reasons for using day care services (Donath et al., 2011; Lecovich \& Biderman, 2013). There is evidence to suggest that family carers have much to gain from the attendance of their loved one at day centres. The respite from caring responsibilities for even a few hours each week can impact positively on the resilience and coping of carers (Donath et al., 2011). Despite the potential benefits of day care, some older adults refuse to attend. The most common barriers cited for nonattendance are stigma associated with receipt of care (Fitzpatrick \& McCabe, 2008), depression (Mavall \& Malmberg, 2007) and deficient transportation (Lecovich \& Biderman, 2013). 


\section{Research aims and objectives}

This study explored the experiences and perspectives of community psychiatric nurses, day centre managers and social workers about supporting clients living with and without dementia attending a generic day care service. The purpose of the study was to elucidate approaches that enable clients living with dementia to access and derive benefit from the service.

\section{Design and Methods}

A descriptive qualitative research design incorporating focus group methodology for data collection was utilised to meet the aim and objective of the study. Focus groups are commonly used in health and social care research to generate data that can illuminate perspectives, clinical practice experiences and challenges encountered (Curtis \& Redmond, 2007; Walden, 2012). A rationale for using focus groups was the anticipation that many of the participants would be known to each other and that knowledge would be generated through conversation (Larkin et al., 2006; Krueger \& Casey, 2008). The primary focus was on the everyday experience of community psychiatric nurses, day centre managers and social workers. In keeping with this approach, a flexible mix of open questions and prompts were developed to enable the researcher to generate discussion, actively listen, and be responsive to what was of value to the participants (Walden, 2012). Such an approach had potential to yield rich data that may illuminate a range of perspectives and everyday experiences of supporting clients with dementia.

\section{Participants}

The context of the study is a statutory generic day centre service for older adults operated by a Health and Social Care (HSC) Trust in the United Kingdom. It is estimated that 2717 people are living with dementia in the HSC Trust. The statutory day centre service is firmly established, with the majority of the centres providing care Monday to Friday each week, across a mix of rural and urban communities. Day centre managers have responsibility for ensuring standards of care and safety of clients. The professionals with a key responsibility for referring older adults living with dementia to the service are community psychiatric nurses and social workers. The experiences and perspectives of these professional groups may be able to generate a greater understanding about approaches that are supportive to clients with dementia, receiving care in a generic older adult day centre service. 
Community psychiatric nurses, day centre managers and social workers meeting the inclusion criteria of i) Trust employees, and ii) two years' experience in current role, were contacted and provided with information about the study. An invitation to participate was distributed by email with the instruction to contact the researchers for further information. Forty of the professionals responded to state their interest in the study, and subsequently met with the researchers. They were provided with more detailed written information about the study, and concerns and queries raised were addressed. In total, twenty agreed to participate, comprising community psychiatric nurses $(n=4)$, day centre mangers $(n=4)$ and social workers $(n=12)$.

\section{Data Collection}

A total of three focus groups were held, with each involving 6 - 9 participants, and a mix of the three professions. The focus groups were conducted in February and March 2014, by the second author (PMcG) in a conveniently located administration building. A facilitation style encouraged contributions from all the participants. Open questions were utilised to stimulate and guide the discussion. Prompts were primarily used to affirm participants and probe deeper into the issues raised and underpinning values and beliefs. Each focus group was recorded digitally with supplementation in hand written notes. The duration of the focus groups ranged from 50-70 minutes. Towards the end of each focus group an opportunity was afforded to the participants to clarify discussion points.

The main aim of the focus groups was to engage directly with the day to day work experiences. The key questions were: Tell me about the day centre service with regards to supporting clients living with dementia?, Describe a typical working day?, What are the issues and challenges that you encounter in your role? Prompts used were 'tell me more about that', 'what was that like for you, ... for the client with dementia, ....for the family carer'.

\section{Ethical procedure}

Ethics approval was granted for the study in line with research governance requirements (Ulster University/ORECNI ref13/0191). The main ethical considerations related to voluntariness, ensuring informed consent, confidentiality, and adhering to data protection requirements. The principle of voluntariness was highlighted to participants, and each participant signed a consent form before the commencement of the focus groups. All data generated in the study were stored securely in accordance with research governance. 


\section{Procedure for data analysis}

The data were analysed informed by Colaizzi's (1978) framework. The framework, involving seven progressive steps, is highly cited in the literature as a means to aid the extraction, organisation, and analysis of qualitative data pertaining to experiences (Speziale \& Carpenter, 2007; Pare et al., 2015; Abalos et al., 2016). The focus group recordings were listened to in full, in order to gain a sense of the whole. Next, they were transcribed and printed. During the transcribing process, participant names were replaced with a numerical code (P1, P2, P3, ..). The printed transcripts were then read and reread independently by two of the authors (EL, $P M c G)$. Significant statements pertaining to enabling clients living with dementia to access and derive benefit from attendance at the generic day centre service were identified independently and extracted. In the third step, the two authors (EL, PMcG) came together to compare and discuss the extracted statements. Through a process of critical dialogue, they reached consensus and formulated meaning to each of the statements. Next, they grouped the meanings into categories and identified clusters of themes. In the fifth step, the clusters were coded to reflect all possible meanings, and weaker structures were combined in the generation of stronger themes. An exhaustive description of supporting clients with dementia to access and derive benefit from attendance at a generic day centre service is encapsulated in the five main themes. These are 'easing the transition to day centre care', 'proactively managing supervision and complexity of need', 'sustaining the person and family carer', making the best of what we have' and 'encountering a need for change'. The themes were then presented and summarised in a face-to-face meeting with a sub-sample of eight of the study participants, critical feedback was encouraged. The themes were verified. Such member checking supports the credibility of qualitative data (Curtis \& Redmond, 2007).

\section{Findings}

The experiences and perspectives of community psychiatric nurses, day centre mangers and social workers about supporting clients living with and without dementia attending a generic day care services are presented under five themes derived from the analysis of the focus group interviews. These are 'easing the transition to day care', proactively managing supervision and complexity of need', 'sustaining the person and family carers', 'making the best of what we have' and 'encountering a need for change'. 
Theme 1: Easing the transition to day care

The data conveyed a sensitivity to new clients and approaches used to ease the transition to day care. There was an understanding that commencing day care may be unsettling for some clients. Emphasis was placed on facilitating the formation of socially supportive relationships that would nurture and support clients. The life story of clients was perceived to be a useful aid in the formation of supportive relationships and client groups, and for forward planning of meaningful social and recreational activities.

'When they first come to day care, it's just that they are out of their own house and this suddenly unsettles them' (P5).

'The more information we have before they come to the day centre the better. If we have their life story, then we can talk to them about it and do activities with them' (P11).

'You are looking at your client list to see who is coming in, and from your observations and knowing the clients, to sort of group them, who comes in, and on what days' (P13).

Home visits prior to day centre attendance presented a significant opportunity for assessing the client's cognitive functioning and his/her social needs.

'You'll get so much benefit from that home visit, because you will see the person, you'll see the home environment. You will get a sense very quickly from talking to them as to their level of cognition and what kind of group they will fit into, who they might mix with, so that is essential (P19).

In addition, prospective clients were encouraged to visit: 'we ask them to come down and have a wee look round first' (P1). The value of such a visit was that 'they get a feel for it and maybe they will recognise someone, and that makes them feel more contented' (P11). Reluctant prospective clients were encouraged to consider commencing their attendance on a trial basis. The trial could constitute the client staying a few hours, getting their dinner and going home again' (P9) and was considered to 'work well'. 
Theme 2: Proactively managing supervision and complexity of need

Clients attending the day centre service are living with physical disability, dementia, intellectual disability and/or mental health problems' (P1) and receive a mix of 'physical and social care, and recreational support from day centre staff' (P10). Day centres constituted convenient satellite units within their communities that afforded opportunities for a range of health and social care professionals including district nurses, community psychiatric nurses and social workers to access clients with complexity of need.

'The nurses will know when they are getting their personal care attended to, and will come in to do dressings. So day centres are acting like a satellite unit, for a lot of professionals to call through, including ourselves' (P14).

The data conveyed that supervision issues arise within the generic service, and that these require pro-active management.

'If you're taking someone into your care you need to meet their needs and particularly for someone in the early stages of dementia that can be wandering and things like that. Staff have one eye on something and the other eye on the doors; just to make sure that everybody is safe' (P15).

'I allocate a half hour supervision slot to each staff member, so it is their responsibility to keep an eye on him at that time, but to be honest when they are in and mixed, integrated, they settle in the very best, not a bother at all and they kind of keep an eye out for each other' (P11).

It was acknowledged that the complexity of client need infrequently presents a challenge to other clients.

'When someone attending the day centre is unsettled, the others will quite quickly vote with their feet and decide not to attend for a day or two' (P20).

The data revealed the formulation of challenging behaviour 'as an unmet need' (P7) and an understanding that clients with behaviours that had potential to challenge others, have much to gain from day centre care: 'If it's an unmet need at home, day centre attendance may sustain them in their homes, a bit longer' (P4). It was acknowledged that day centre staff 'do an amount of challenging behaviour work, but not really in-depth' (P11). The data conveyed support and tolerance for the mix of clients (with and without dementia) attending day care together. 
'We don't have dementia specific day centre care we just have them integrated; so it's all about social interaction and integration with other people (P10).

'They can say what they like and they are not pulled up on it. The other clients are not passing any remarks' (P13).

A readiness to support clients with advanced dementia was also conveyed. There was an understanding that this client group 'may need more one to one interaction' (P1).

'Considering the research we're getting on life story work and reminiscence therapy. One to one life story work would work really well' (P2).

\section{Theme 3: Sustaining the person and family carer}

Day centre care was perceived to have positive psychosocial impact on the client with dementia, and to therefore be 'therapeutic in its own right' (P5). It was highlighted that day care attendance fosters a 'sense of purpose and a sense of belonging' (P16) that not only sustained clients with dementia, but slowed down progression of cognitive impairment.

'It's the routine that's sustaining them. Their memory could be cognitively impaired but they have been at day care for a long time. If the placement was thrown into jeopardy, this would cause a significant change for somebody who has had that routine for years' (P5).

'I think day centre care can prolong the period of mild to moderate dementia stage. They have something different to talk about when they go home and it gives them more independence to be there, and to get their hair done. The day centre staff can take them to the chiropodist or wherever they need to go. I think it does really help them a lot in the early stages. It holds dementia back' (P13).

'Music and singing is particularly uplifting for them' (P4).

'For clients with dementia, the opportunity to sing and listen to music can bring them back' (P11).

The participants placed emphasis on sustaining the relationship between the family carer and the client with dementia, which they understood had potential to become 'intense'. The respite provided by day centres was perceived to be 'crucial to carers' (P19) and 'invaluable for maintaining the client in a community setting (P2). 
'We have a lady at the moment with dementia, and her husband while she was in with us, went to sleep, because she was 24/7 at home. She needed a lot of one to one. Day centre attendance for his wife gave him a wee break. He was under a lot of pressure' (P13).

Participants highlighted an increasing trend for clients to be living alone. They perceived that when 'family members are living many miles away from the client, or residing and working in another country' (P9), that 'the feedback provided by the day centre staff is very important' (P1).

'Day centre staff pick up quickly on changes and concerns, and report these on to the social worker and general practitioner as appropriate for assessment and management, and to the family' (P8).

Participants perceived that their feedback offered reassurance to the family that their relative is cared for and safe

\section{Theme 4: Making the best of what we have}

The urban day centre service is operated from large multi-purpose Trust buildings. In contrast, the rural centres are accommodated in leased public halls. When multi-function buildings are simultaneously used by different groups in the community, participants conveyed that this could reduce stigma and fear, by impacting positively on the local community's view of ageing.

'They are seeing us and we are talking to them. They are looking in through the door even though they do not use the service, and it's not a scary service anymore' (P11)

The physical environment of the rural centres was described as 'general space' (P4) with 'very sterile and grey colours' (P2). It was acknowledged that 'none of the centres are designed or adapted for people with dementia' (P4). The data conveyed an increasing awareness that environmental design can have an enabling or disabling impact on clients with dementia.

'It's all relatively new and being recognised now. Hands up last week it was the first time I thought about the toileting thing. Toilet bowls are white, floors are white and everything is white. It's a toilet space and they are urinating into a space where they think they should' (P15) 
'We went out and bought coloured cups and coloured plates. The walls in our day centre would have been all creams, but we worked very hard to get the colour scheme more warming, welcoming, colourful, bright and cheery' (P13).

It was highlighted that in the centres with access to a garden, 'in the good weather we have our tea out in it, and we have grown tomatoes and strawberries' (P1). The participants shared a sense of pride that despite physical environmental deficits, such as the absence of a garden, they had found creative ways to 'bring the garden in' (P9): 'We don't have a garden, but we ensure that there's always flowers on the walkway in' (P8).

It was illuminated that 'we are making the best of what we have' (P13). Social interaction and a range of recreational activities were supported. Rural centres were perceived to have an advantage over urban centres because 'many of the clients are farmers and they know each other' (P2) and 'they go over and talk to each other and ask them things you know; it's all friends' (P1).

Opportunities for outside activities, such as shopping and eating meals out were available and supplemented the bringing in of outside groups, schools and voluntary agencies to support the provision of stimulating activities and social engagement. An underpinning philosophy was conveyed, that 'there is always something that a client can do' (P1). Activities available in some of the centres included 'bowls, skittles, box, armchair exercises, yoga, arts and crafts, music, bingo and gardening in the good weather' (P1). A contention was put forward that 'lt's all about being creative and using what you have' (P11).

'You have to see what level they are at, there is always something they can do like jigsaws or reading out poems, stories or reminiscence for themselves, if they are not able to interact with the group' (P1).

\section{Theme 5: Encountering a need for change}

The data illuminated that most clients travelled to and from day centres in a designated bus. Travel time restrictions coupled with a prohibition on attaining day centre services outside of the Trust catchment area created a layer of inequity that prohibited some older adults from accessing the service. Rural populations were perceived by the participants to be particularly affected by travel time restraints. 
'I have ones who would actually be closer to (named town). We can't obviously cross into another Trust to access their day care. She is outside the 10-mile radius so she can't access the day care we have' (P19).

"It's not that they can't get the bus because of their dementia; it's because of the rural location where they live and its distance from that Trust's nearest day centre' (P4).

Another area of inflexibility in the system was a standard day centre attendance allocation of two days each week. Whilst this allocation was perceived to afford an equitable entitlement whereby 'everybody has an opportunity' (P1), the participants illuminated that after a few years, family carers will request a third day. it was clear that participants experience a level of frustration when they found themselves unable to meet such requests.

'It needs to be personalised. I have one lady, she just loved the bus drive and the day care experience and her family wanted to sustain her at home and her dementia was progressing and her mobility was reducing. But we hit a brick wall because she had 2 days' (P14).

Such experiences affirmed an understanding that the service must become more responsive and attain greater flexibility if it is to meet the future needs of the growing number of clients with dementia. There was an expectation that the service will need to adapt and changes anticipated included an extension of 'opening hours in the evening because of all the sun downing behaviours' $(P 3)$, and 'incorporating a rapid response in 'emergency and crisis situations' (P9).

'There are sometimes emergency situations and crisis situations that we could provide the service for, instead of putting someone into a nursing home' (P19).

A rationale for change towards a more overt focus on rehabilitation was also provided:

'Things like toileting regimes could be developed in day centre care and brought out to the home to promote level of independence' (P5).

'It would be good if you had facilities for people to have their own kitchen and things like that' $(P 1)$. 


\section{Discussion}

This study sought to explore the experiences and perspectives of community psychiatric nurses, day centre managers and social workers about supporting clients living with and without dementia attending a generic day care service. The study elucidated approaches that enable clients living with dementia to access and derive benefit from such a service. Five key themes emerged from the study: 'easing the transition to day care', 'proactively managing supervision and complexity of need', 'sustaining the person and family carer', making the best of what we have' and 'encountering a need for change'. These broad themes will now be discussed with reference to the international literature on the topic.

The data conveyed a generic service aligned to an integrated day care model designed to deliver on assessment, treatment, care and social needs (Lecovich \& Biderman, 2013). The participants described approaches for enabling prospective clients to ease the transition from home to attendance at a day centre, including home visits to prospective clients, and the encouragement of prospective clients to visit the centre on a trial basis. An emphasis was placed on fostering relationships, and ascertaining life stories to inform plans for meaningful activities and social groupings at the day centre. Life story work is a hallmark of quality in the dementia trajectory as it has potential to affirm personhood and promote positive cultures of care (Gibson, 2011). It was therefore encouraging in our study to find that professionals are acknowledging the contribution that such work can bring to care planning.

An interesting finding was the perception that the local community's view of ageing and dementia was positively influenced when day care was operated from buildings that were simultaneously used by several community groups. Similar findings have been reported within an intellectual disability context. In an Australian study, Bigby (2010) found that older people with intellectual disabilities valued active engagement with their local community, suggesting that generic older peoples' services may play an increasingly important role in supporting a diverse range of client groups including people living with dementia and intellectual disabilities. Dementia strategies place emphasis on social integration and participation. Whilst there were indications that the mix of clients with and without dementia can pose some challenges for staff and clients, our data revealed that day centre managers are finding ways to proactively plan for effective supervision. Challenging behaviour was formulated as unmet need, in line with Kitwood (1997) and Cohen-Mansfield (2000), and consistent with previous day care research (Mossello et al., 2008), it was conjectured by our participants that clients with challenging behaviour may have most to gain from day centre attendance. They perceived that the routine of day centre attendance was therapeutic in its own right, and sustained clients with dementia by slowing down the progression of cognitive impairment. Previous research 
has indicated that adults with dementia do respond well to consistency and routine (Weir \& Fouche, 2015). Opportunity to engage in meaningful social interaction is highly valued by day centre clients (Brataas et al., 2010; Dabelko-Schoney \& King, 2010). Our data indicated a range of recreational activities that are available to clients. Recreational activities have potential to foster senses of purpose and belonging (Nolan et al., 2006; Dabelko-Schoney \& King, 2010; Weir \& Fouche, 2015). The participants in our study highlighted that music and singing were particularly uplifting for clients with dementia, and had potential to 'bring them back'. Research conducted by McDermott et al. (2014) has affirmed that listening to music can support personal psychology.

There is a broad consensus in the international literature on family caregiving that day care services, designed to meet the needs of service users and families, are central to the wellbeing of family carers and to their ability to continue a caregiving role (Droes et al., 2004; Schacke \& Zank, 2006; Graff et al., 2008). Findings from the present study conveyed a sympathetic understanding of the complexity of family caregiving relationships in the dementia trajectory, and of the importance of day respite for people living with dementia and their family carers (Mavall \& Malmberg, 2007; Mossello et al., 2008; Donath et al., 2011). The participants in our study also highlighted that day care attendance was particularly important for reassuring family members who lived some distance away, that their relative was safe. This finding was not anticipated, and is pertinent in light of international migration trends (Raghuram, 2012; Rajan \& Balagopal, 2017).

The ability of day care services to respond to the changing needs of clients living with dementia and their family carers is highly regarded by service users (deJong \& Boersma, 2009; Donath et al., 2011). The participants in our study were encountering travel time restrictions that may disproportionally affect rural populations, and a rigid day care attendance allocation. They were anticipating that the service will need to change and become more responsive to client need. They also anticipated a shift towards an overt focus on rehabilitation. In light of the environmental design issues conveyed in our results, it would be difficult to envisage how a rehabilitation model of day centre care could be operationalized, without investment in physical design change. Our overall finding is that a generic day care service that provides a blend of care, treatment, social support and recreation, and attended by older adults living with and without dementia is of value, and is feasible and realistic.

The day care service that provides the context of this study is situated in the UK and was resourced by a Health and Social Care Trust. In line with international ageing demographics (United Nations, 2015), global alliance on healthy and active ageing (World Health Organisation, 2012) and strategy towards social inclusion (Alzheimer's Disease International, 2016), it is anticipated that demand for generic day care services for clients living with 
dementia will increase internationally. However, day care for older adults as a concept in the current fiscal climate in the UK and internationally faces many challenges (Bird \& Bird, 2016; Rajan \& Balagopal, 2017; Van Eenoo et al., 2016). In Europe, there is a shift away from government and not for profit organisation funding of day care towards private for profit organisational funding (Van Eenoo et al., 2016), with Germany leading the way with $63 \%$ of community care for older adults now provided by private for-profit organisations. In India there has been an unprecedented rise in day care services operated by charitable organisations and private nursing homes in recent years, with no regulatory regime in place to set and appraise standards (Rajan \& Balagopal, 2017). In a climate of tight fiscal restraints, our study conveys that it is feasible and realistic to operate a generic older adult day centre service attended by both clients living with and without dementia in leased public halls and multipurpose buildings, and indeed that such a strategy may have potential to influence positively the views of the public about ageing and reduce stigma.

\section{Limitations of the study and future recommendations}

The focus groups were conducted and analysed with community psychiatric nurses, day centre managers and social workers who have working experience of supporting clients to access and attend a generic older adult day centre service. A possible limitation of the study is that many of the participants were known to the co-author (PMcG) in her role as a senior social worker, and this may have affected how participants responded during the focus groups. All of the focus group recordings were transcribed and submitted to the data analysis process. The initial extraction of the key statements and recurring themes was conducted by both PMcG and EL independent of each other, and this measure limited the potential for bias. Despite acknowledged limitations, the data generated were rich and illuminating and have resulted in interesting findings that have international significance. Day centre care is important given ageing demographics, increasing prevalence of dementia among populations and international migration trends of younger generations, and our findings have shed light on the approaches that support the attendance of clients living with dementia in a generic older adult day centre service for clients. A recommendation for future research in this area would be to include the perspectives of service users and family carers.

\section{Conclusion}

This study has elucidated approaches that enable clients living with dementia to access and derive benefit from a generic day centre service attended by clients with and without dementia. 
The key findings in our study are the importance that participants placed on an integrated and socially inclusive service, and an evident sense of pride that the service was contributing positively to the lives of clients and their families. In addition, the blend of care, treatment and social support provided by the service would appear to have some value. The study findings affirm the important contribution of generic day care services in an ageing society. Whilst the data revealed deficits in the physical environment of the centres, there were indications of a positive social environment. The respect and value placed on knowing the clients and fostering relationships with and between clients and with family carers, was reflective of a relationship-centred care approach. The implications of the study are a need a need for services to be more flexible and responsive to the needs of clients and carers. Evidence of inequity in service provision particularly affecting rural populations warrants the urgent attention of service managers and planners. Day care services will experience increasing pressure in demand, due to global migration and ageing trends. This study has found that a generic day centre service that provides an integrated blend of care and treatment and social and recreational support to older adults living with and without dementia, is realistic and manageable.

\section{Implications for practice}

This study affirms the contribution of interdisciplinary team working involving community psychiatric nurses, social workers and day centre managers in community care with older adults. Approaches to support the attendance of clients with dementia at a generic day care service include home visits, life story work, pro-active supervision and careful planning of social groupings and recreational activities. Promoting day care attendance is an approach to healthy and active ageing.

\section{Acknowledgement}

The researchers express their gratitude to all who participated in this study for giving of their time, despite competing commitments.

\section{Contributions}

Study design: EL, PMcG, data collection PMcG, data analysis: EL, PMcG, AR, important contextual content BR, and manuscript preparation EL, PMcG, BR, AR. 


\section{References}

Abalos E.A., Rivera R.Y., Locsin R.C. \& Schoenhofer S.O. (2016) Husserlian Phenomenology and Colaizzi's Method of Data Analysis: Exemplar in Qualitative Nursing Inquiry Using Nursing As Caring Theory. International Journal for Human Caring 20, 19-23.

Alzheimer's Disease International (2012) National Alzheimer and Dementia Plans, Planned Policies and Activities, Early Detection, Access to Diagnosis, and Stigma Reduction. Available at: $\quad$ https://www.alz.co.uk/sites/default/files/national-alzheimer-and-dementia-plans.pdf (accessed 3 January 2016).

Alzheimer's Disease International (2016) Dementia friendly communities: the principles. Available at: https://www.alz.co.uk/adi/pdf/dfc-summary-sheet.pdf (accessed 23 January 2016).

Bigby C. (2010) A Five-Country Comparative Review of Accommodation Support Policies for Older People with Intellectual Duisabiliyty. Journal of policy and Practie in Intellectual Disabilities 7(1), 3-15. Doi: 10.1111/j.1741-1130.2010.00242.x..

Bird G., \& Bird J. (2016) 'No Place like Home' - The Human Rights of Women in Aged Care. In J.A. Scutt Ed. Women, Law and Culture. Buckingham: Palgrave Macmillan.

Brataas H.V., Bjugan H., Wille T., \& Helizwen O. (2010) Experiences of day care and collaboration among people with mild dementia. Journal of Clinical Nursing 19, 2839-2848.

Cahill S., O'Shea E. \& Pierce M. (2012) Creating Excellence in Dementia Care: A Research Review for Ireland's National Dementia Strategy. Trinity College, Dublin.

Chalfont G. (2011) Charnley Fold: A practice model of environmental design for enhanced dementia day care. Social Care and Neurodisability 2, 71-79.

Cohen-Mansfield J. (2000) Use of patient characteristics to determine non-pharmacologic interventions for behavioural and psychological symptoms of dementia, International Psychogeriatrics 12, 373-380.

Colaizzi P.F. (1978): Psychological research as the phenomenologist views it. In: Valle RS, King M (eds) Existential phenomenological alternatives for psychology. Oxford University Press, New York. 
Curtis E. \& Redmond R. (2007) Focus groups in nursing research. Nursing Research 14, 2537.

Dabelko-Schoney H. \& King S. (2010) In their own words: participants' perceptions of the impact of adult day services. Journal of Gerontological Social Work 53, 176 - 192.

Day K. Carreon D. \& Stump C. (2000) The therapeutic design of environments for people with dementia: a review of the empirical research. The Gerontologist 40, 397-416.

De Jong J.D. \& Boersma F. (2009) Dutch psychogeriatric day-care centers: a qualitative study of the needs and wishes of carers. International Psychogeriatric Association 21, 268-277.

Donath C., Winkler A., Graessel E. \& Luttenberger K. (2011) Day care for dementia patients from a family caregiver's point of view: A questionnaire study on expected quality and predictors of utilisation. BMC Health Services Research 11, 1472-6963.

Droes R.M., Meiland F., Schmitz M., van Tilburg W. (2004) Effect of combined support for people with dementia and carers versus regular day care on behaviour and mood of persons with dementia: results from a multi-centre implementation study. International Journal of Geriatric Psychiatry 19(7), 673-84.

Fitzpatrick T.R. \& McCabe J. (2008) Future challenges for day centre programming to serve younger and more active baby boomers. Activities, Adaption and Ageing 32, 198-213.

Gibson F. (2011) Reminiscence and Life Story Work. $4^{\text {th }}$ edn. Jessica Kingsley, London.

Graff M.J.L., Adang E.M.M., Vermooii-Dassen M.J.M., Dekker J., Jonnson L., Thiissen M., Hoefnagels W.H.L., Olde Rikkert M.G.M. (2008) Community occupational therapy for older patients with dementia and their care givers: cost effectiveness study. British Medical Journal 336(7636), 134-138. Doi: 10.1136/bmj.39408.481898.

Grove S. K., Burns N., \& Gray J.R. (2013) The practice of nursing research: Appraisal, synthesis, and generation of evidence (7th ed.). Elsevier, St. Louis.

Kitwood T. (1997) Dementia Reconsidered: The Person Comes First. Open University Press, Buckingham, UK.

Krueger R.A. \& Casey M.A. (2008) Focus Groups: A Practical Guide for Applied Research. Sage, London.

Larkin M., Watts S., Clifton E. (2006) Giving voice and making sense in Interpretative Phenomenological Analysis. Qualitative Research in Psychology 3, 102-120. 
Lecovich E. \& Biderman A. (2013) Attendance in adult day centres of cognitively intact older persons: reasons for use and non-use. Journal of Applied Gerontology 32, 561 - 581.

Mavall L. \& Malmberg B. (2007) Day care for persons with dementia. Dementia 6, 27-43.

McDermott O., Orrell M. \& Ridder H.M. (2014) The importance of music for people with dementia: the perspectives of people with dementia, family carers, staff and music therapists. Ageing and Mental Health 18, 706-716.

Mossello E., Caleri V., Rassi E., Baru M.D., Cantini C., Tonon E., \& Masotti G. (2008) Day care for older dementia patients: favourable effects on behavioural and psychological symptoms and caregiver stress. International Journal of Geriatric Psychiatry 23, 1066-1072.

Nolan M., Brown J., Davies S., Nolan J. \& Keady J. (2006) The Senses Framework: Improving Care for Older People Through a Relationship-centred Approach. University of Sheffield: Sheffield.

Pare J. (2015) Understanding the Lived Experiences of Nurses Working in Critical Access Hospitals. American Research Journal of Nursing 1, 2379-2922 Available at: https://www.arjonline.org/papers/arin/v1-i5/1.pdf (accessed 6 December 2015).

Raghuram P. (2012) Global care, local configurations - challenges to conceptualizations of care. Global Networks 12, 155-174.

Rajan S. I. \& Balagopal G. (2017) Elderly Care in India. Springer: Singapore.

Schacke C. \& Zank S.R. (2006) Measuring the effectiveness of adult day care as a facility to support family caregivers of dementia patients. Journal of Applied Gerontology 25(1), 65-81.

Speziale H.J. \& Carpenter D.R. (2007) Qualitative Research in Nursing: Advancing the Humanistic Imperative, (4th ed.). Lippincott, Williams and Wilkins, Philadelphia.

Thomas D. (2006) A general inductive approach for analysing qualitative evaluation data. American Journal of Evaluation 27, 237-246.

Tse T. \& Howie L. (2005). Adult day groups: addressing older people's needs for activity and companionship. Australian Journal on Ageing, 24, 134- 140.

United Nations (2015) World Population Ageing Report. Available at: http://www.un.org/en/development/desa/population/publications/pdf/ageing/WPA2015 Repo rt.pdf (accessed 23 January 2017) 
Van Eenoo L., Declercq A., Onder G., Finne-Soveri, H., Garms-Homolová V., Jónsson P.V., Dix O.H.M., Smit J.H., van Hout P.J., van der Roest H.G. (2016) Substantial between-country differences in organising community care for older people in Europe-a review. European Journal of Public Health 26 (2), 213-219. Doi.org/10.1093/eurpub/ckv152.

Walden G. (2012) Focus Group Research. Sage, London.

Weir A. \& Fouche C. (2015) Community-based dementia day programmes: Common elements and outcome measures. Dementia, pii: 1471301215590504.

Whisnant Turner K. (2004) Senior citizens centers: what they offer, who participates and what they gain. Journal of Gerontological Social Work 43, 37-47.

World Health Organisation (2012) Knowledge Translation Framework for Ageing and Health. Available at: http://www.who.int/ageing/publications/knowledge translation.pdf?ua=1 (accessed 6 May 2016) 